\title{
Identifying more about customers: the phenomenon of the switch to the knowledge exchange
}

Ewa Ziemba, Faculty of Finance and Insurance, University of Economics in Katowice, Poland, ewa.ziemba@ue.katowice.pl

Roisin Mullins, Faculty of Business and Management, University of Wales Trinity Saint David, Great Britain, r.mullins@uwtsd.ac.uk

\begin{abstract}
The purpose of this study is to explore how the customer knowledge management systems support business follow-up of customer reviews and discussion using social media, and propose a customer stratification framework. The survey methodology was used to collect the data utilized in answering the research questions and based on the analysis and logical deduction, a conceptual customer stratification framework was proposed. This framework explains the stages required by a business to observe customers social media discussions starting with validation where business should aim to better understand how customers map themselves onto other customer experiences. Secondly, the reinforcement stage is where business should explore how the customer is better informed to make choices from the customer's discussions. Finally, through the contradiction stage the business should recognise the value placed to explore where they are weak and have a means to correct these areas.
\end{abstract}

Keywords: customer knowledge, social media, customer knowledge management, knowledge about customer, knowledge from customers

\section{Introduction}

The attention and importance placed on gleaning and analysing knowledge about customers, and from customers is gaining increased prominence especially in recent times with the growth in the interaction with social media by customers for active business engagement. Integrating social media with knowledge management allows businesses to engage with customers in innovative ways (Duan, 2013; Paroutis \& Al Saleh, 2009; Najafloo, Rasouli, \& Shamizanjani, 2015; von Krogh, 2012; Zhang, 2011). Further, Chua and Banerjee (2013) have analysed how "the use of social media can support customer knowledge management (CKM) in an organisation". Social media including techniques such as discussion and reviews are important tools used by CKM that can help firms gain knowledge from and about customers (Ford \& Mason, 2013; Taherparvar, Esmaeilpour, \& Dostar, 2014; Zembik, 2014). In these reviews and discussion, diverse people with different levels of knowledge can articulate their needs, problems and doubts (Maswera, Dawson, \& Edwards, 2006), and enterprises can use this knowledge to make sense of community perspectives to develop new ideas, improve current products and services, and 
launch new and innovative products and services. Ziemba and Eisenbardt (2015a, 2015b) proposed and examined the conceptual framework of customers' participation in business processes by means of social media and using reviews and discussion.

The exchanging of knowledge is an important aspect of being a member of a community and customers voluntarily contribute knowledge increasing the prospective customer's awareness of the products and services offered by the business (Kumar, Aksoy, Donkers, Venkatesan, Wiesel, \& Tillmanns, 2010). Further, businesses hold the desire to acquire information and customers have accelerated this rise in information sharing by posting reviews onto social media business web sites (Choi \& Shah 2014). Customers appraise other customer's reviews, and customers appraise the business response. There are important questions to raise about this knowledge exchange. Firstly, who has possession over the response? Essentially it is both the business and the customers at the same time, and this is where the knowledge switch happens. The business allows self-stratification on the part of the customer, but how much is reflected back through the business and do the knowledge management systems or CKM support this exchange?

The customer is empowered by the internet's social media capabilities which allow them to leave comments and reviews for other customers to appraise and respond to, but current research shows that public organisations, as well as many private businesses, may still be at an early stage in using social media and Web 2.0 and Sivarajah, Irani, and Weerakkody (2015) present the benefits, risks and impact of these tools for individuals as well as the organisation including policy issues referring to responsibility and control. The business has two options; one is to observe the (review and discussion) commentary and stay relatively quiet (Kietzmann, Hermkens, McCarthy, \& Silvestre, 2011). Secondly, the business may choose to interact directly with the customer in a highly transparent way, using the social media, for other customers/prospective customers to grasp how the business responds. Through either of these options, the customer has the upper hand in informing others about how they feel about the business offerings.

Businesses employ a variety of tools to analyse the text in the knowledge exchange (Gémar and Jiménez-Quintero, 2015). Harrysson, Metayer, and Sarrazin (2012) present a viable range of analytical toolkits designed for contemporary business competitive objectives. Further, widely available text analysis tools such as Mallet may be adopted to analyse the discussion or WEKA for deeper data mining or tools embedded in the cloud services such as TripAdvisor and Google Analytics. There are licence agreements with 3rd party cloud analytics tools, so it's not possible to analyse the customer information exchange away from these embedded tools limiting the choice of analysis to the functions available. On a larger scale data warehouses use Hadoop, MapReduce and other software for data mining, analysing, visualising and reporting are implemented for analysis.

The authors of this paper, after extensively searching the literature, did not uncover any deep studies about how the CKM support business follow-up of customer reviews and discussion using social media. This reveals a need for studying how customer reviews and discussion should be used in enterprises and how these may impact upon and affect the success of business. This research should contribute to greater understanding of the use of customer reviews and discussion in enterprises and should help fill the gap in the existing body of knowledge. 
In light of the above limitations, the objectives of this study are to explore how the CKM support business follow-up of customer reviews and discussion using social media and propose a customer stratification framework. The paper is organised as follows, a theoretical supposition, followed by a brief methodology, reporting of the findings leading to discussion and conclusion.

\section{Theoretical Background}

\section{Using consumer knowledge in business}

Business contending with new challenges presented by the knowledge era will understand that knowledge is its most strategic resource and the basis of competition and survival in competitive environments. Moreover, customer knowledge takes on greater significance in light of these challenges (Masa'deh, Gharaibeh, Tarhini, \& Obeidat, 2016; Taherparvar et al., 2014). Customer knowledge becomes an essential intangible asset for every line of business (Rowley, 2002), leads to better response and respect to customers (Aghamirian, Dorri, \& Aghamirian, 2013), and contributes to the improvement of business value (Croteau \& Li, 2009). The business ability to manage customers' knowledge should be considered as a potential source of competitive advantage. It is aligned with Gilbert, Leibold, and Probst's (2002) statement that CKM constitutes a continuous strategic process by which companies enable their customers to move from passive information sources and recipients of products and services to empowered knowledge partners.

CKM is the application of knowledge management instruments and techniques to capture, share, transfer, and apply knowledge related to customers. It can be realized at three levels (Vecchio \& Ndou, 2012; Ziemba, 2013):

- knowledge for customers, represented by knowledge about markets, products and suppliers that support customers in their buying cycle and impacts on customers' perception of an enterprise and its offers;

- knowledge from customers, defined as ideas, thoughts, and information that the enterprise receives from its customers and uses them to enhance its products and services; and

- knowledge about customers, encompassed the customers' needs and requirements, future expectation and desires, connections, purchasing activity and financial capability.

CKM generally supports the exchange of knowledge not only between an enterprise and its customers, but also between enterprise's customers (Najafloo et al., 2015). The emerging Web 2.0 and social software applications open a new horizon for enterprises to exchange customer knowledge, and this process can be achieved in various ways and by means of different information technology.

\section{Using customer reviews and discussion for exchanging customer knowledge}

Some studies show that social media can be used for knowledge management (Bharati, Zhang, \& Chaudhury, 2015; Chua \& Banerjee, 2013; Ford \& Mason, 2013; Heller-Baird \& Parasnis, 2011; 
Levy, 2009; Zhang, 2011). Only a few of them explore the application of social media for exchanging customer knowledge. For example, Starbucks redefined the roles of its customers through the use of social media by transforming them from passive recipients of beverages to active contributors of innovation. Moreover, Starbucks uses effective strategies to mitigate customers' unwillingness for voluntary knowledge sharing, thereby promoting engagement in social media (Chua \& Banerjee, 2013). Gafni, Geri, and Bengov (2014) investigated the effect of tangible and virtual rewards for knowledge contribution in online communities.

Using social media customers can review and discuss an enterprise and its offers. Further, customer reviews and discussion can be important ways for exchanging customer knowledge, especially knowledge from and about customers. Reviews and discussion mainly embrace thoughts, opinions, comments, rankings and pools of products and services, future needs and ideas for product and service innovation (Ziemba \& Eisenbardt, 2013). Studies conducted in Poland reported that almost 38\% of customers 'strongly and rather often' exchange their knowledge on products and services through reviews and discussion. Furthermore around 82\% of customers 'strongly and rather often' look for reviews and discussion on the Web and use them as advice before making their own purchase decisions.

\section{Customer stratification and profiling}

Encouraging social discourse between customers increases the chance for businesses to capture knowledge and they have to take care to make a 'measured' response to the open discussion. It is at this juncture, the 'knowledge exchange' where the knowledge switch occurs because the business gain from the customers involvement and prospective customers are in a strong position to determine if the customer base matches theirs and if the business is credible to engage with. Both customer-to-customer and customer-to-business become conveyors of knowledge, but the knowledge does not necessarily fit into a system or knowledge management approach.

The body of customer reviews represent essentially a population (Anand, Glick, \& Manz, 2002), There is a population of characteristics, and a visitor try's to tie their experience in with the different conditions (Hilligoss \& Rieh, 2008). A customer ties in the characteristics they want, then maps those on to the cluster of conditions or contributions (Huo \& Palmer, 2015). As a customer you are mapping the kind of thing you would say, and mapping your expectations onto other people's experiences (Morris, Counts, Roseway, Hoff, \& Schwarz, 2012). When a customer identifies commonality between their experiences and wishes, then the customers are interested in that product/service.

On the other hand, if a customer cannot identify with any part of the population of experiences, then they are a lot less likely to be interested in that product/service. It is no different to when a customer chooses to enter a bar for the first time, customers tend to look for people dressed like them, same mood as them, subconsciously look for similar economic classification such as economic wealth, and make a decision about whether one wants to associate with the place/product, so it is no different online. In real life, a customer is making decisions based on their social and financial conditions. In that case, a customer will be stratifying or profiling themselves by that means (Huo \& Palmer, 2015). Essentially a customer takes the favourable aspects of a product review and uses that as a starting point for a fresh search. The social media 
reviews allow customers to draw from other people's experiences to enhance their enquiry, to get exactly what they want from the knowledge exchange. The knowledge exchange encourages 'companies to get close to customers' referred to by Heller-Baird and Parasnis (2011), and importantly they state that 'using social media as a channel for customer engagement will fail if the traditional CRM approaches are not reinvented.'

Stratifying oneself to something you want to purchase, or finding out more about the product/service is a very good weapon in the customer's armoury. A good business will follow up on it. But it is unlikely that business follows up, and it begs the question how much of the follow-up is being analysed by the business? Business needs to ensure they are conducting this follow-up, through a sophisticated post analysis approach to this pool of experimental information in the knowledge exchange. Following on from the suggestion by Heller-Baird and Parasnis (2011) it is clear businesses need to look at how to manage this approach and move thinking forward.

\section{Research Methodology}

An initial pilot survey with 30 businesses was conducted in stages of increasing detail and exactitude to address the reliability of the research strategy adopted. Reliability was addressed by undertaking the pilot survey or pretest to ensure issues such as validity and bias could be reviewed and also to ensure repeatability of the results when the survey was repeated following corrections with the same 30 businesses. The repeatability of the questionnaire was high and acceptable to be used for the main survey.

The initial pilot survey with 30 businesses was conducted to assess if the four questions were phrased appropriately and to determine if the options for responding seemed appropriate. This approach was deemed necessary to ensure the questionnaire measured what it intended to measure. As a result following the pilot survey, the forth question was rephrased and simplified to reduce ambiguity. Further, the sample included a range of businesses from a variety of sectors and sizes to limit researchers concerns about participant representation.

The final survey was presented to a total of 3120 business in Wales following their completion of a variety of contemporary business training courses. Out of the total surveyed, 1024 (the response rate was 33\%) of the businesses completed the survey. The survey was conducted in February-June 2014.

The survey considered four main research questions:

RQ1: Do you need training in embedding social media onto your business web site to capture customer reviews and discussion, and if so what level of training is needed (choose from: No need for training, Basic training, Advanced training)?

RQ2: Do you have a social media strategy in place?

RQ3: Do you respond to customers who post reviews and discussion on your social media?

RQ4: Do you analyse the customer reviews and discussion? 


\section{Research Findings}

The survey method was used to design structured questions while accepting that this is a less detailed observational data approach on a relatively large number of businesses and the data collected was then subjected to standard forms of analysis (Quine \& Taylor, 1998).

The data and open responses were captured on paper-based questionnaires for analysis. Alongside capturing descriptive statistical data, it was deemed sensible to use a supporting qualitative tool such as document coding to capture items from the questions. The responses were scanned and themes identified. In this way, the themes are broken down into unambiguous, mutually exclusive and exhaustive, sets so that any individual response portion could be assigned to just one theme. The commonly occurring themes were noted. The coded themes are reported in Table 2 under the column methods of reviews and discussion analysis.

The findings support significant knowledge outcomes detailing how business respond to customers posting and responding to messages and encouraging this social-tie between customers and the business.

The businesses surveyed reported how the enterprise benefits from the knowledge gleaned from customers but were unsure of the methods required to conduct follow-up analysis and link to CKM and enterprise systems.

From a total of 1024 businesses who attended a range of business training courses and responded to a survey where they were asked four questions. Table 1 summarises questions 1-3 and Table 2 reports on question 4 .

\section{Needs for training in capturing customer reviews and discussion}

A high proportion of the businesses surveyed $78 \%$, indicated they had no need to engage in social media training, at any level (Table 1). Suggesting they had employed social media in an efficient and useful way in their business. These should be referred to as 'high level' users. A second group emerged and referred to as 'intermediate' level users, a total of $9 \%$, reporting they required advanced training in using social media indicating that the basic use of the tools had been satisfied, but additional forms of engagement and analysis would be required to benefit the business. A final group reporting 'beginner' level training, 13\% of enterprises reported that had not embarked on embedding social media into the business web site or using separate social media sites for increasing their business visibility to a wider audience. 
Table 1: Training business using social media to capture customer reviews and discussion

\begin{tabular}{|l|l|l|}
\hline \multicolumn{1}{|c|}{$\mathbf{7 8 \%}$ of enterprises } & \multicolumn{1}{|c|}{$\mathbf{9 \%}$ of enterprises } & \multicolumn{1}{c|}{$\mathbf{1 3 \% \text { of enterprises }}$} \\
\hline No need for training & Need advanced level training & Need beginner level training \\
\hline $\begin{array}{l}\text { Using a wide variety of social media } \\
\text { embedded on the web site. }\end{array}$ & Some use of social media & $\begin{array}{l}\text { No social media embedded on the } \\
\text { web site }\end{array}$ \\
\hline $\begin{array}{l}\text { Strategy in place } \\
\text { Business explained they are } \\
\text { continually looking at how to update } \\
\text { the strategy - borrowing ideas from } \\
\text { other businesses }\end{array}$ & No strategy in place & No strategy considered \\
\hline $\begin{array}{l}\text { Respond to customers reviews/issues } \\
\text { customers reviews/issues }\end{array}$ & $\begin{array}{l}\text { Hid not allow customers an online } \\
\text { means to exchange information } \\
\text { with the business }\end{array}$ \\
\hline
\end{tabular}

\section{Having social media strategy in place}

The high level users had a strategy in place whereas the intermediate level, and beginner levels did not have a social media plan or strategy in place (Table 1). The training required proposed the need to ensure that tactics and strategy in using social media for business and customer discourse is a priority.

\section{Responding to customers who post reviews and discussion on social media}

The high level social media users reported that they do respond to customer's reviews and discussion (Table 1). The intermediate businesses had not responded to customers on any occasion, and the beginner businesses did not have any social media in place and did not engage with customers through social media tools. 


\section{Analysing customer reviews and discussion}

The responses to this question are summarised in Table 2 below.

Table 2: Comparison of methods of customer reviews and discussion analysis based on enterprise size

\begin{tabular}{|c|c|c|c|}
\hline $\begin{array}{l}\text { Methods of reviews } \\
\text { and discussion } \\
\text { analysis }\end{array}$ & Small enterprises & Medium enterprises & Large enterprises \\
\hline $\begin{array}{l}\text { Customer reviews } \\
\text { and discussion }\end{array}$ & $\begin{array}{l}\text { Not skilled to } \\
\text { analyse expect to } \\
\text { rely on } 3^{\text {rd }} \text { part } \\
\text { analytics tools } \\
\text { embedded in tools } \\
\text { such as Trip } \\
\text { Advisor }\end{array}$ & $\begin{array}{l}\text { Use 3rd party analytics tools and } \\
\text { where reviews are captured on } \\
\text { business web site - use open } \\
\text { Source tools such as R, Mallet and } \\
\text { databases and external Business } \\
\text { Intelligence and analytics expertise }\end{array}$ & $\begin{array}{l}\text { 3rd party analytics tools } \\
\text { and where reviews are } \\
\text { captured on business web } \\
\text { site - use Hadoop, } \\
\text { databases and external } \\
\text { Business Intelligence and } \\
\text { analytics expertise }\end{array}$ \\
\hline Approach & Manual & Manual and analytical & Analytical \\
\hline $\begin{array}{l}\text { Current method of } \\
\text { follow-up }\end{array}$ & $\begin{array}{l}\text { Automated through } \\
\text { 3rd party tools }\end{array}$ & $\begin{array}{l}\text { Automated through 3rd party tools } \\
\text { Where responses are made on } \\
\text { business own web site this is done } \\
\text { through a classification approach } \\
\text { based on the type of positive and } \\
\text { negative issues reported by the } \\
\text { customer }\end{array}$ & $\begin{array}{l}\text { Automated through 3rd } \\
\text { party tools }\end{array}$ \\
\hline $\begin{array}{l}\text { In-house discussion } \\
\text { of response to } \\
\text { method of follow-up }\end{array}$ & $\begin{array}{l}\text { Little discussion it } \\
\text { would be very time } \\
\text { consuming }\end{array}$ & $\begin{array}{l}\text { Some discussion in quarterly } \\
\text { planning meetings about method } \\
\text { used but no discussion of response } \\
\text { to follow-up }\end{array}$ & $\begin{array}{l}\text { Departmental team } \\
\text { meetings for planning } \\
\text { No discussion of response } \\
\text { to method of follow-up }\end{array}$ \\
\hline Updating strategy & $\begin{array}{l}\text { No change to } \\
\text { strategy }\end{array}$ & $\begin{array}{l}\text { Recognise a need to inform } \\
\text { changes to strategy but not } \\
\text { underway }\end{array}$ & $\begin{array}{l}\text { Early stages of defining } \\
\text { opportunities for strategic } \\
\text { formulation }\end{array}$ \\
\hline $\begin{array}{l}\text { Analysing customers } \\
\text { reviews and } \\
\text { discussion for } \\
\text { promoting } \\
\text { reinforcement of } \\
\text { issues }\end{array}$ & None & $\begin{array}{l}\text { None - manual and low level } \\
\text { analytics proposed but not } \\
\text { implemented }\end{array}$ & $\begin{array}{l}\text { Early stage of creating } \\
\text { algorithms for } \\
\text { identification and analysis }\end{array}$ \\
\hline
\end{tabular}

The data captured suggests that businesses of all sizes do not have sophisticated methods in place for post analysis of customer reviews. Consequently, they are not in a position to explore this pool of experimental information. There is a recognised need to address how to move things forward, and how to ensure the methods of analysis and follow-up of the experimental information are incorporated into the business enterprise systems or CKM systems.

A case may be made to state that the businesses are not in charge anymore, the customer has the upper hand as a result of the internet knowledge exchange. 


\section{Customer stratification framework}

An important suggestion is that the business or "most organizations do not possess all required knowledge within their formal boundaries and must rely on linkages to outside organizations and individuals to acquire knowledge" (Anand et al., 2002), and the business is no longer in control of the knowledge exchange giving the customer the upper hand. The business can, therefore, be put in a corner, relating knowledge to a circumstance of wishing to buy something. The internet has empowered the customer to make the decision. The businesses do need not necessarily need to be concerned about how important the customer's position is in a network which is often recorded as an important factor (McLure Wasko \& Faraj, 2005), but it is about increasing the customer stratification information that better informs the customer groups. This is best explained in Figure 1 through three stages of activity which the business have to develop an approach to.

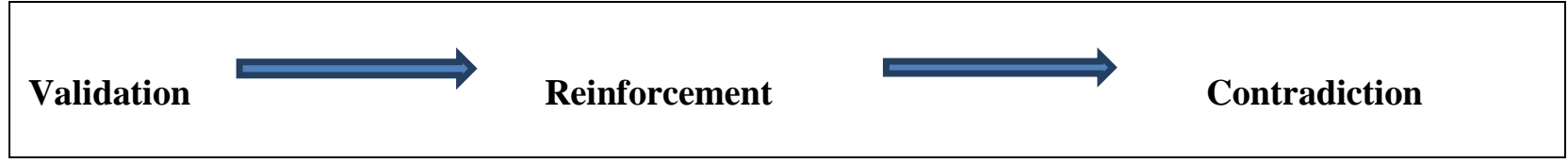

Figure 1: Customer stratification framework

The research findings inform the three stages of a customer stratification framework where the customer's views coded in themes are established as separate stages of a business review process.

\section{Validation}

When a customer visits a site, with a mix of positive and negative reviews posted, as a customer you look at how they were articulated and what they meant to explain, if they are continually positively reinforced it enforces a customer to feel positive, this is a natural response, so there is a discourse going on between the customers. The individual coming to it will align themselves with either the positive or negative reviews based on their mapping of themselves and based on the perception of the population of contributors. Then the customer's feels more aligned to a customer group because of the way the reviews were articulated. It allows for the substantiation of why the review of a product or service was good or bad and allows the future entrant to weight all this up.

This stratification framework suggests that customers map themselves to the pool of experimental evidence. It is clear that the business of each size, small, medium and large are at an early stage in determining how much is mirrored back through the business systems, and this informs an important area for further research.

\section{Reinforcement}

The customer can make an informed and enriched decision because of the social exchange; they do not need to talk to anyone. In the past, it was through a recommendation from a friend of a family member, but this has changed, and now the reviews and (like/dislike) buttons are ticked 
as the customer exchange is via the Internet social media. For example, a customer thinking about a holiday will review sites such as TripAdvisor, where there may be a high volume of customer posts.

\section{Contradiction}

If a business is trying to sell that hotel experience, they should be harvesting the most common words from customer reviews, most common on favourable feedback and inserting that in the literature, while the negative issues would be the focus of the internal meetings, otherwise this is going to hurt the business. The business needs to resolve what is bad and improve on what is good and then the business will have a better product and be more competitive. The business becomes successful because of several things that are good but require access to fulfilling the knowledge exchange follow-up through new internal to external processes.

It is well known that a business is not taken down by a single weakness, and in that case, the issues can be addressed, and they need to identify the areas that are weak. None of this customer stratification could have happened before the knowledge exchange via social media. It has always happened because of normal social processes. However, the amount and complexity of the information have been enhanced by orders of magnitude because of social media and the means to stream data and information via the Internet.

\section{Conclusions}

\section{Summary of findings and research contribution}

This paper is one of the first to find empirical support for the role of CKM within businesses and explore how customer reviews and discussion posted via social media can be used by businesses. The conceptual framework of customer stratification shows how business should use customers reviews and discussions for gaining knowledge about and from customers. This study can provide valuable insights and guidance for researchers and practitioners as well.

The customer search and profiling can be referred to as customer stratification, and the approach to this needs to be addressed if businesses value customer knowledge exchanges.

The link between the knowledge exchange and CKM or enterprise systems may not be well aligned as the customer reviews tend to follow similar themes indicating the business has not followed up adequately.

So the follow-up from external reviews to knowledge management systems for reporting and further analysis is probably weak.

There may also be a different approach to follow-up from small to medium to large businesses and for each the follow-up approach will be conducted by different tools, methods, rules and processes, but the analysis must be performed to provide the business with the chance to regain the upper hand.

It is most likely that the small company will continue to conduct the follow-up through manual methods depending on the size and skills of the employees, and the sector they are associated with, the medium size business will conduct this by a mix of manual, cloud services and (in- 
house or outsourced) business analytics methods. The large businesses will most likely have the process fully automated alongside implementing internal/business analytics methods.

\section{Limitations of the research}

As one of the first studies empirically investigating the relationship between social media (especially customers reviews/ discussions) and customer knowledge management, this study was exploratory in nature and certainly with some limitations. Firstly, it was limited to Wales and thus its generalization has obvious geographical limitation and does not account for countryspecific differences. Secondly, although the survey method was appropriate for testing the theoretically deducted research issue, there are some limitations. For example, survey respondents generally provide a positive evaluation of their own enterprises and this may bias surveys. While the authors made efforts to ensure that the respondents are knowledgeable and experienced to answer questions, the results are still based on their perceptions and not on measurable output. Moreover, the research questionnaire includes only basic questions leading to explore how the customer knowledge management support business follow-up of customer reviews and discussion using social media. Thirdly, the proposed framework of customer stratification is the first development of an ongoing research study that needs to be deepened and widened, to cover the implementation of social media for customer knowledge management.

\section{Implications for practitioners and researchers}

Despite these limitations, this study has significant implications for both practitioners and researchers. The expectation of the paper is to encourage deeper insight into the area of CKM with the theoretical assurance necessary to improve the practical concerns for modern customer focused businesses and invest in the analytical follow-up approaches. As more enterprises consider the application of social media for customer knowledge management, this study should interest practitioners. It shows that social media, especially such techniques as customer reviews and discussion can be used by business to exchange customer knowledge, and present opportunities to enhance products and services offered, and create new ones. Thus, this study highlights that social media strategy, knowledge of social media and the analysis of customer reviews and discussions are necessary to gain and use customer knowledge for enhancing businesses.

For researchers, this study contributes to a better understanding of the intersection of social media, and customer knowledge management. Researchers who develop research on using social media for managing customer knowledge could find reliable guidelines in this paper.

\section{Possible areas for future research}

Findings from this study suggest many opportunities for future exploration in this area. Among the many possibilities, a deep exploration of proposed customer stratification framework seems most interesting and promising. 


\section{References}

Aghamirian, B., Dorri, B., \& Aghamirian, B. (2013). Effects of customer knowledge management's eight factors in e-commerce. Management Science and Engineering, 7(4), $1-11$.

Anand, V., Glick, W. H., \& Manz, C. C. (2002) Thriving on the Knowledge of Outsiders: Tapping Organizational Social Capital, Academy of Management Executive, 16(1), 87101.

Bharati, P., Zhang, W., \& Chaudhury, A. (2015). Better knowledge with social media? Exploring the roles of social capital and organizational knowledge management. Journal of Knowledge Management, 19(3), 456-475.

Choi, D., \& Shah, C. (2014). Perceived value of information sharing in online environments: User engagement and social reputation. The Information Association for the Information Age ASIS\&T 2014 Annual Meeting. Retrieved April 01, 2016, from https://www.asis.org/asist2014/proceedings/submissions/.../146paper.pdf.

Chua, A.Y.K., \& Banerjee, S. (2013). Customer knowledge management via social media: The case of Starbucks. Journal of Knowledge Management, 17(2), 237-249.

Croteau, A.-M., \& Li, P. (2003). Critical success factors of CRM technological initiatives. Canadian Journal of Administrative Sciences, 20(1), 21-34.

Duan, W. (2013). Special issue on social media: an editorial introduction. Decision Support Systems, 55(4), 861-862. (is this

Ford, D.P., \& Mason, R.M. (2013). Knowledge management and social media: The challenges and benefits. Journal of Organizational Computing and Electronic Commerce, 23(1/2), $1-6$.

Gafni, R., Geri, N., \& Bengov, P. (2014). Investigating the effect of tangible and virtual rewards on knowledge contribution in online communities. Online Journal of Applied Knowledge Management, 2(2), 1-11.

Garcia-Murillo, M., \& Annabi, H. (2002). Customer knowledge management. Journal of the Operational Research Society, 53(8), 875-884.

Gémar, G., \& Jiménez-Quintero, J. A. (2015). Text mining social media for competitive analysis. Tourism \& Management Studies, 11(1), 84-90.

Gibbert, M., Leibold, M., \& Probst, G. (2002). Five styles of customer knowledge management, and how smart companies use them to create value. European Management Journal, 20(5), 459-469.

Harrysson, M., Metayer, E., \& Sarrazin, H. (2012). How 'social intelligence' can guide decisions. McKinsey Quarterly, 4, 81-89.

Heller-Baird, C., \& Parasnis, G. (2011). From social media to social customer relationship management. Strategy \& Leadership, 39(5), 30-37. 
Hilligoss, B., \& Rieh, S. Y. (2008). Developing a unifying framework of credibility assessment: Construct, heuristics, and interaction in context. Information Processing \& Management, 44(4), 1467-1484.

Huo, Q., \& Palmer, A. (2015). Analysing voluntary contribution to online forums using a proposed critical mass contribution model. The Journal of Applied Business Research, 31(2), 687-700.

Kietzmann, J. H., Hermkens, K., McCarthy, I. P., \& Silvestre, B. S. (2011). Social media? Get serious! Understanding the functional building blocks of social media. Business Horizons, 54(3), 241-251.

Kumar, V., Aksoy, L., Donkers, B., Venkatesan, R., Wiesel, T., \& Tillmanns, S. (2010). Undervalued or overvalued customers: Capturing total customer engagement value. Journal of Service Research, 13, 297-310.

Lesser, E., Mundel, D., \& Wiecha, C. (2000). Managing customer knowledge. Journal of Business Strategy, 21, 35-37.

Levy, M. (2009). WEB 2.0 implications on knowledge management. Journal of Knowledge Management, 13(1), 120-134.

Masa'deh, R., Gharaibeh, A.H., Tarhini, A., \& Obeidat, B.Y. (2016). Knowledge sharing capability: A literature review. Journal of Business \& Management, 4(1), 1-13.

Maswera, T., Dawson, R., \& Edwards, J. (2006). Assessing the levels of knowledge transfer within e-commerce websites of tourist organisations in Africa. Electronic Journal of Knowledge Management, 4(1), 59-66.

Morris, M. R., Counts, S., Roseway, A., Hoff, A., \& Schwarz, J. (2012). Tweeting is believing?: understanding microblog credibility perceptions. Proceedings of the Conference on Computer Supported Cooperative Work - ACM 2012, pp. 441-450. Seattle, WA, USA, February 11 - 15, 2012.

McLure Wasko, M., \& Faraj, S, (2005). Why should I share? Examining social capital and knowledge contribution in electronic networks of practice author(s). MIS Quarterly, 29(1), Special Issue on Information Technologies and Knowledge Management, 35-57.

Najafloo, F., Rasouli, H., \& Shamizanjani, M. (2015). CKM:2.0: Integarting Web 2.0 into customer knowledge management. In Khanlari, A. (ed.), Strategic customer relationship management in the age of social media, pp. 130-154. Hershey: IGI Global.

Panni, M.F.A.K. (2012). CKM and its influence on organizational marketing performance: Proposing an integrated conceptual framework. In Kaufman, H.R., Panni, M.F.A.K. (eds.), Customer-centric marketing strategies: Tools for building organizational performance, pp. 103-125. Hershey: IGI Global.

Paroutis, S., \& Al Saleh, A. (2009). Determinants of knowledge sharing using Web 2.0 technologies. Journal of Knowledge Management, 13(4), 52-63.

Quine, S., \& Taylor, R. (1998). Methodological strategies. In C. Kerr, R. Taylor, \& G. Heard (Eds.) Handbook of Public Health Methods, pp. 17-23. Sydney: McGraw-Hill. 
Rowley, J. (2002). Eight questions for customer knowledge management in e-business. Journal of Knowledge Management, 6(5), 500-511.

Sivarajah, U., Irani, Z., \& Weerakkody, V. (2015). Evaluating the use and impact of Web 2.0 technologies in local government. Government Information Quarterly, 32(4), 473-487.

Taherparvar, N., Esmaeilpour, R., \& Dostar, M. (2014). Customer knowledge management, innovation capability, and business performance: A case study of the banking industry. Journal of Knowledge Management, 3(18), 591-610.

Vecchio, P., \& Ndou, V. (2012). Customers knowledge and relational marketing: A Web 2.0 perspective. In Eir, R. (ed.), Successful customer relationship management programs and technologies: Issues and trends, pp. 131-144. Hershey: IGI Global.

von Krogh, G. (2012). How does social software change knowledge management? Toward a strategic research agenda. The Journal of Strategic Information Systems, 21(2), 154-164.

Zembik, M. (2014). Social media as a source of knowledge for customers and enterprises. Journal of Applied Knowledge Management, 2(2), 132-148.

Zhang, Z. (2011). Customer knowledge management and the strategies of social software. Business Process Management Journal, 17(1), 82-106.

Ziemba, E. (2013). Conceptual model of information technology support for presumption. In Proceedings of International Conference on Management, Leadership and Governance - ICMLG 2013, pp. 355-363. Bangkok University, February 07-08, 2013.

Ziemba, E., \& Eisenbardt, M. (2013). Prosumption awareness among young consumers. Studia Ekonomiczne, 153, 163-177.

Ziemba, E., \& Eisenbardt, M. (2015a). Examining prosumers' participation in business processes. Polish Journal of Management Studies, 12(1), 219-229.

Ziemba, E., \& Eisenbardt, M. (2015b). Prosumers' participation in business processes. Online Journal of Applied Knowledge Management, 3(1), 114-127.

\section{Authors' Biographies}

Ewa Ziemba completed her Ph.D. and Post Ph.D. in Management, with a major focus on management information systems. She is an Associate Professor at the University of Economics, Katowice, Poland. Her current research focuses on information systems and technologies for business and public administration transformation. She has published over 160 peer-reviewed papers and 13 books and has played an instrumental role in prestigious Polish and international research projects. Ewa Ziemba serves on the editorial boards of several international journals and is the Founding Editor-in-Chief of The Online Journal of Applied Knowledge Management. She is also the Vice President for Research Collaborations of the International Institute for Applied Knowledge Management. Ewa Ziemba has received numerous awards for research and teaching, including The Excellent Award of the President of the University of Economics in Katowice, The Silver Cross of Merit from the President of Poland, The Medal of the National Education Commission from the Ministry of National Education in Poland, and The Award of Fellow \& 
Distinguished Scholar from the International Institute for Applied Knowledge Management, and several The Best Papers awards.

Roisin Mullins completed her Ph.D. in the development and evaluation of e-learning systems, learning communities and business training systems. She has published over 40 peer-reviewed pieces including conference papers, book chapters, and international journal papers. Roisin Mullins serves on the editorial boards of several international conferences. Her research has emphasized practical solutions to technology problems or novel applications of technology, so that in addition to answering a question, the research outcomes have informed policy and practice guidelines at the European level and decision making processes in the SMEs of EU member countries. 